\title{
INDÚSTRIA CULTURAL E MÚSICA GOSPEL: REFLEXÕES SOBRE A PRÁTICA RELIGIOSA DO SÉCULO XXI
}

\author{
Cultural Industry and Gospel Music: \\ Reflections on 21st Century Religious Practice
}

Eliton Perpetuo Rosa Pereira ${ }^{1}$

Márcia Rodrigues Trigueiro ${ }^{2}$

RESUMO: Utilizada nas práticas litúrgicas, a música gospel, que no início teria sua função específica intrínseca à religião, apresenta-se também como um seguimento de mercado. Com base no pensamento adorniano, buscamos investigar a presença da indústria cultural no contexto da música religiosa, expondo seus aspectos imanentes e as contradições sociais resultantes. $\mathrm{O}$ presente estudo é uma pesquisa qualitativa, com escopo exploratório e descritivo. Através de uma análise de conteúdos de reportagens, entrevistas e um grupo focal com músicos do contexto religioso, a pesquisa buscou compreender as contradições da cena gospel. A pesquisa aponta para a função da formação musical crítica.

PALAVRAS-CHAVE: Música. Cultura. Religião. Formação Crítica.

ABSTRACT: Used in liturgical practices, gospel music, which at first would have its specific function intrinsic to religion, also presents itself as a market merchandise. Based on the Adornian thought, we seek to investigate the presence of the cultural industry in the religious music context, exposing its immanent aspects as well as the resulting social contradictions. The present study is a qualitative research, with an exploratory and descriptive scope. Through an analysis of contents of reports, interviews and a focus group with musicians from the religious context, the research sought to understand the contradictions of the gospel scene. The research points to the function of critical musical formation.

KEYWORDS: Music. Culture. Religion. Critical Formation.

\footnotetext{
${ }^{1}$ Doutor em Ciências da Educação pela Universidade de Santiago de Compostela (USC-Espanha). Licenciado e Mestre em Música pela Escola de Música e Artes Cênicas da Universidade Federal de Goiás (EMAC-UFG). Especialista em Tecnologias em Educação (PUC-RJ). No Instituto de Educação, Ciência e Tecnologia de Goiás (IFG-Brasil) atua na Licenciatura em Música - Campus Goiânia. Tem experiência em Educação Musical, Canto Coral, Metodologia Científica e Formação de Professores.

${ }^{2}$ Mestranda em Artes pelo IFG/UDESC. Licenciada em Música pelo IFG. Possui vários cursos na área eclesiástica. Atua como educadora musical e como cantora profissional
} 


\section{INTRODUÇÃO}

O percurso histórico do capitalismo aliado ao desenvolvimento das ciências tecnológicas acarretou mudanças, tanto nos meios de produção - configurando a produção em massa, quanto no modo de vida econômico, político, social e cultural das sociedades ocidentais. Nesse cenário, a indústria cultural também produz em larga escala a arte, visando a lucratividade inerente ao mercado capitalista. Assim, a indústria cultural abarca, dentre outras manifestações artísticas, a música (TAME, 1984; NOGUEIRA, 2014).

$\mathrm{Na}$ atualidade, as comunidades religiosas ${ }^{3}$, principalmente as denominadas como cristãs, têm a música como componente essencial em suas reuniões e práticas litúrgicas. Com mensagens baseadas na fé e com ensinamentos teológicos de concepções variadas, "a música utilizada nos cultos atua como elemento de comunhão com o sagrado e entre os fiéis e, ao mesmo tempo, serve para estabelecer e conservar a identidade do grupo" (MARTINOFF, 2010, p. 72). Com o tempo, a música das práticas litúrgicas passou a compor também as emissoras de rádio, ficando assim, conhecida por música gospel.

A música de entretenimento, essencialmente produzida pela indústria cultural, tendo em vista o capital, objetiva manipular também o seu ouvinte, ou seja, tanto o produto é padronizado quanto o seu consumidor, nesse caso, consumidor cultural (ADORNO e HORKHEIMER, 2002). Considerando a configuração da música gospel em um segmento de mercado (MARTINOFF, 2010; CUNHA, 2007; PAULA, 2012), esta pesquisa propôs atribuir à formação musical, o descerramento de possibilidades a favor da formação crítica, a qual potencializa o alcance da autonomia.

O objetivo geral da investigação foi compreender a relação entre indústria cultural e música gospel e os aspectos dialéticos desse contexto. Os objetivos específicos que nortearam a pesquisa foram: utilizando-se de um método dialético como reflexão crítica, identificar elementos que testificam a presença da indústria cultural no contexto da música gospel, e propor a educação musical crítica como instrumento de formação emancipatória.

Em razão de ser uma temática pouco discutida, o presente trabalho possui caráter exploratório e descritivo e, apresenta-se com uma abordagem qualitativa por tratar de fenômenos sociais. Inicialmente apresentamos as categorias da dialética, da indústria cultural e educação

\footnotetext{
${ }^{3}$ A pesquisa identificou as categorias discutidas inicialmente nas igrejas cristãs protestantes, contudo é patente no contexto religioso de vários seguimentos, a relevância da música em suas práticas litúrgicas.
} 
musical, expostas a partir de um referencial teórico voltado para a compreensão da historicidade e das relações desses itens com a temática investigada (RODRIGUES, 2014).

Posteriormente, apresentamos a reunião de dez reportagens sobre música gospel que denunciam inversão de valores e alienação no contexto desta música; entrevistas (SZYMANSKI, 2004) e um grupo focal (GATTI, 2012), ambos com sujeitos do universo eclesiástico que trabalham diretamente com a música. A interpretação dos dados coletados se deu com base na Análise de conteúdo de Franco (2012) e Bardin (2011).

\section{DIALÉTICA E INDÚSTRIA CULTURAL}

Segundo Konder (1994, p. 7) dialética no sentido contemporâneo "é o modo de pensarmos as contradições da realidade, o modo de compreendermos a realidade como essencialmente contraditória e em permanente transformação". Um exemplo de pensador dialético na Grécia antiga $^{4}$ foi o filósofo Heráclito de Éfeso (540 a.C. - 470 a.C.), que defendia que o ser está em constante mudança e que as realidades opostas se transformam umas nas outras. Georg Hegel (1770 - 1831) também foi um filósofo importante para o pensamento dialético. Hegel retoma as ideias de Heráclito entendendo que tudo é movimento e mudança, assim, tudo depende de tudo e é relativo ao todo. As contradições fazem parte da mesma realidade, onde o ser e o não ser pertencem à mesma coisa (LAKATOS E MARCONI, 1992).

Rodriguez (2014) afirma que os marxistas entendem que a realidade é objetiva, e que a matéria existe antes e independentemente da consciência humana. Diferente do pensamento idealista, a matéria é quem produz o pensamento. Marx e Engels desenvolveram princípios para a dialética, instituindo o Materialismo histórico dialético como método de compreensão da realidade.

[...] o materialismo histórico dialético considera a cultura e a identidade imbricadas ao trabalho. Mediante o trabalhado, o homem transforma a natureza, por consequência, as relações econômicas, produtivas e sociais propiciam a construção da identidade, bem como a criação e a recriação da cultura (RODRIGUEZ, 2014, p. 140).

Em Adorno a dialética continua, por assim dizer, essencial para compreender a realidade, ainda se constituindo de fundamentos contraditórios que se relacionam entre si, porém com destaque à negatividade, ou seja, a negatividade é que movimenta a dialética. Constrói-se então, a

\footnotetext{
${ }^{4}$ Ver também o papel da Ironia e da Maiêutica em Sócrates (469 a.C. - 399 a.C.).
} 
expressão Dialética negativa que se desprende da sua condição afirmativa e assume a negação em caráter contínuo, confrontando a imutabilidade e o finito. A dialética negativa é uma metodologia de reflexão e intervenção à consciência humana deformada pela realidade social refletida do capitalismo tardio (PUCCI, OLIVEIRA e ZUIN, 2008).

Segundo Pucci, Oliveira e Zuin (2008) Adorno defende que a resistência ao processo de coisificação da consciência começa na reflexão crítica e, que é da falta desta que descende a alienação e a degeneração da consciência. A perspectiva da dialética negativa está voltada para o novo e na investigação da diferença entre pensamento e realidade, e é essa dissemelhança que gera a reflexão crítica responsável pelo processo de emancipação.

\subsection{Indústria Cultural}

Em 'A dialética do esclarecimento', Adorno e Horkheimer (1985) identificaram a razão instrumental como agente causador das destruições da segunda grande guerra. Onde o saber científico passa a ser assumido como verdade absoluta, se constituindo em ferramenta de dominação do homem sobre outros homens (BORGES, 2011). O progresso técnico permite que as forças produtivas sejam privilégio de poucos e assim, aqueles que não as possuem se veem coagidos a negociar sua mão de obra. Aqueles que detêm o saber detêm também domínio sobre a natureza, contudo caminham numa linha estreita de opressão e dominação sobre a sua própria espécie. O que seria esclarecimento, na verdade tornou-se ferramenta de alienação (BORGES, 2011).

O avanço tecnológico gerou mudança nas forças produtivas, resultando no processo de Revolução industrial, e assim, emergindo o chamado Capitalismo industrial. A necessidade de se produzir em grande escala, com prioridade soberana no lucro, gerou mudanças no modo de produção, afetando diretamente o modo de vida da sociedade. O caráter e as leis do capitalismo refletem no homem, o influenciando e o transformando em produto, em mercadoria (ADORNO e HORKHEIMER, 2002). Tudo se torna produto de troca, com valores de troca, valores submissos aos interesses do mercado. Por conseguinte, os reflexos do capitalismo industrial atingem também a esfera das artes. Nesse momento nasce a discussão sobre a Indústria cultural, conhecida também como cultura de massa, que alcança todos os seguimentos de manifestação artística: música, artes plásticas, cinema, entre outros. 
Adorno e Horkheimer criaram o conceito "indústria cultural" para nomear a modalidade de arte destinada ao consumo de massa. Trata-se de um produto elaborado não mais segundo o padrão e a escala do trabalho artesanal, mas conforme o esquema capitalista de produção de mercadorias, no qual o valor de uso é reduzido à condição de mero suporte do valor de troca. (MUSSE, 2015, p. 215).

Sobre esse sistema de produzir cultura para as massas, transformar a arte em mercadoria, trata-se efetivamente de um negócio e os lucros adquiridos por essa produção confirmam a intenção de manipular a necessidade e o gosto dos consumidores. Não obstante, a indústria cultural se justifica por possibilitar à grande massa, o acesso à arte e à cultura (ADORNO e HORKHEIMER, 2002).

Na realidade, o marco da indústria cultural está na alta capacidade de falsamente democratizar o acesso a bens duráveis e culturais no sentido de enfraquecer o espírito crítico, bem como de combalir a organização coletiva combativa contra o sistema. Isso, enfim, abrange o investimento em uma formação de mentalidade que ressoa no condicionamento de sujeitos adaptados e conformados. (ZANOLLA, 2013, p. 103).

Surge então, nesse contexto, a propaganda que, através da televisão e do rádio, das imagens e sons, sugerem valores, significados e a primazia aos produtos; conduzindo o indivíduo a receber e a aceitar como sendo verdade e, ainda, sem reflexão precedente, a consumir cada vez mais. A propaganda homogeneíza a sociedade e aboli a diferença, fazendo desta a condição para a exclusão (FRANÇA, 2008). Enfim, a autonomia do artista é restrita e todo esse processo acaba interferindo no real sentido da obra de arte e da arte em si.

Nesse contexto, a música ao ser apropriada por seus algozes, corrobora a massificação do gosto e a consequente perda da individualidade na produção artística, influenciando negativamente a relação entre arte e sociedade, interação que, pelo menos, deveria apontar para a emancipação e a plenitude do belo. (FRANÇA, 2008, p. 5).

Adorno (1983) fala que os produtos da Indústria cultural subestimam a capacidade intelectual do espectador e atrofiam a imaginação e a espontaneidade do sujeito, ou seja, vetam a atividade mental. A arte perde o seu significado próprio e passa a servir ao capitalismo e às suas fontes de produção. Nesse sentido, a arte industrializada é um instrumento de gerenciamento do capitalismo no tempo livre do trabalhador; criada para reconduzi-lo à sua produção, encorajandoo a continuar a produzir para o capital e, mais que isso, silenciando-o e o confinando à passividade (ADORNO e HORKHEIMER, 2002). 


\subsection{Dialética e Indústria Cultural na Música Gospel}

Desde a sua ascensão, “o mercado capitalista vive em permanente expansão, o capital tende a ocupar todos os espaços que possam lhe proporcionar lucros" (KONDER, 1994, p. 34). Nessa perspectiva, podemos destacar o crescimento da indústria fonográfica gospel, a mídia e o avanço do chamado mercado gospel.

A princípio, a música gospel se deu com grupos afrodescendentes norte-americanos no século XIX. As primeiras composições expressavam na música a união com as famílias e comunidades locais, todos pertencentes à um contexto de acentuada exclusão social naquela época; as composições possuíam espontaneidade e cunho emocional (MARTINOFF, 2010). A música gospel perdurou até os dias atuais, e apesar da ser apreciada essencialmente nas comunidades evangélicas e católicas, sua presença tem avançado junto a toda sociedade. Ademais, a presença da música gospel se dá também nos veículos de comunicação como as rádios, a televisão e a internet.

Sob a ótica capitalista, há um crescente interesse econômico de todo o material envolvido nesse contexto na atualidade. Delimitando-se aqui ao segmento, "estima-se que o 'mercado evangélico' no país, movimente mais de três bilhões de reais por ano e crie dois milhões de empregos diretos e indiretos" (MARTINOFF, 2010, p. 68). Para Cunha (2007) existe uma transformação dessa cultura religiosa específica em um tipo de seguimento de mercado. A partir das ideias de Adorno (1983), compreendemos que a música gospel tem sido moldada por seguimentos da indústria cultural e ao mesmo tempo integrado as atividades das instituições e a vida cotidiana dos fiéis.

Esta reflexão passa pela função assumida por essa música como entretenimento, que a indústria cultural produz com fins lucrativos, para além do sentido da música em si vinculada aos princípios originais das práticas litúrgicas. "O empenho dessa indústria centra-se na capacidade de se inverter valores, significados de ideias e conceitos, ao mesmo tempo em que objetiva a produção e o consumo desmedidos" (ZANOLLA, 2013, p. 103). De modo consequente, a manipulação do gosto, das escolhas, e a decorrente transferência de valores capitais não só à cultura religiosa, como à sociedade.

Para mais, Nogueira (2014) reflete sobre os tipos de ouvintes apontados por Adorno, que destacava o ouvinte de entretenimento como sendo o mais numeroso, pois este sustenta e fortalece a indústria cultural na sociedade capitalista. De modo que "o ouvinte do entretenimento 
é aquele pelo qual se calibra a indústria cultural, seja porque ela o engendra ou o traz à tona." (ADORNO apud NOGUEIRA, 2014, p. 307).

A perspectiva dessa pesquisa está voltada à compreensão de que suscitar o pensamento crítico reflexivo, elemento favorável à formação do sujeito, que serve como esforço e busca de enriquecimento da prática religiosa sobre suas próprias concepções e sobre seus próprios valores, impedindo ou dificultando interferências ou modificações por questões externas, alheias aos princípios originais. Assim,

o processo formativo deve estimular a negação e até mesmo a repulsa a toda tentativa de manipulação e produto cultural alienante. Alcançado esse ponto, seria possível falar com clareza em uma sociedade de emancipados, em que os indivíduos tomam para si mesmos a responsabilidade de construir os paradigmas políticos e culturais. Eis, aí, o propósito mais significativo da educação, para o qual ela deve operar com todas as suas forças. (SILVA e SENA, 2015, p. 181).

A reflexão crítica está para o pensamento de resistência que oportuniza a autonomia e o desenvolvimento da consciência humana, do decidir com real liberdade de escolhas.

(...) a prática educativa da comunidade certamente será instrumento eficaz para garantir coerência, qualidade e compromisso diante do atual contexto cultural religioso, sem desprezar ou desqualificar as novidades, mas, sim, como diz o apóstolo Paulo, "retendo o que é bom" (CUNHA, 2007, p. 93).

Para Kater (2004) a educação musical pode auxiliar no processo de formação do indivíduo e oferecer novas concepções de formação humana.

\footnotetext{
Música e educação são, como sabemos, produtos da construção humana, de cuja conjugação pode resultar uma ferramenta original de formação, capaz de promover tanto processos de conhecimento quanto de autoconhecimento. Nesse sentido, entre as funções da educação musical teríamos a de favorecer modalidades de compreensão e consciência de dimensões superiores de si e do mundo, de aspectos muitas vezes pouco acessíveis no cotidiano, estimulando uma visão mais autêntica e criativa da realidade. (KATER, 2004, p. 44).
}

Segundo Grandisk (2009) na perspectiva do teórico Adorno "a formação está como tarefa filosófica e ética para que o ser humano se emancipe e conquiste seu espaço social, cultural, político, por meio do saber e do conhecimento" (GRANDISK, 2010, p. 105). Nesse sentido, a educação musical pode ser instrumento de formação, a caminho da emancipação do sujeito frente à alienação imposta pela indústria cultural e pelo processo massificador do capitalismo (COSTA, 2017; ZANOLLA, 2013). 


\section{METODOLOGIA}

Esta investigação se configura em uma abordagem qualitativa de pesquisa social (RODRIGUEZ, 2014), pois busca compreender, em uma perspectiva crítica, as contradições presentes em um determinado contexto sociocultural. Acredita-se que, por meio desta abordagem, seja possível alcançar os objetivos compreensivos e, mediante os dados teóricos e empíricos, elaborar propostas de intervenção educativa musical no contexto estudado.

Inicialmente elaboramos uma pesquisa documental em publicações retiradas de revistas e jornais eletrônicos, reportagens que manifestam como a música gospel tem se identificado com os procedimentos mercadológicos da indústria cultural. Foram reunidas dez reportagens (links inseridos após as referências).

Posteriormente, foram realizadas entrevistas com seis sujeitos do universo eclesiástico que trabalham com a música gospel. Eles são líderes de grupos musicais responsáveis pelo momento musical na prática litúrgica de igrejas neopentecostais. Entre as atividades que exercem nesses grupos musicais estão a de conduzir os ensaios do grupo musical e decidirem o repertório para o ensaio e, consequentemente, à execução na igreja durante a celebração religiosa. As entrevistas foram conduzidas de acordo com as orientações metodológicas de Szymanski (2004).

Como terceiro grupo de dados da pesquisa, foi elaborado um grupo focal fundamentado nas orientações metodológicas de Gatti (2012). Os participantes envolvidos no grupo focal têm em comum o fato de serem músicos atuantes em suas comunidades, e desenvolvem como tarefa principal a de conduzir o momento musical.

Os dados coletados foram tratados com base na metodologia de Análise de conteúdo de Franco (2012) e Bardin (2011).

\section{ANÁLISE E RESULTADOS}

A pesquisa de campo apresentou três contextos distintos de coleta de dados: 1) A análise de reportagens; 2) A realização de entrevistas; 3) Um grupo focal.

\subsection{Reportagens}

No quadro 1, a seguir, estão organizadas as reportagens reunidas, identificando o título e as categorias definidas para a pesquisa: Dialética, Indústria cultural e Educação musical (esta última está ausente de todas as reportagens). 
QUADRO 1 - Análise preliminar das dez reportagens

\begin{tabular}{|l|l|l|}
\hline \multicolumn{1}{|c|}{ TÍTULO } & \multicolumn{1}{|c|}{ DIALÉTICA } & \multicolumn{1}{c|}{ INDÚSTRIA CULTURAL } \\
\hline $\begin{array}{l}\text { Música gospel: } \\
\text { trinado, fé e dinheiro. }\end{array}$ & $\begin{array}{l}\text { (...) “o mercado gospel alia fé e louvor para } \\
\text { produzir dinheiro". (...) “todos os dias, as } \\
\text { igrejas recebem novos convertidos, que passam } \\
\text { a consumir vorazmente os produtos } \\
\text { evangélicos. E a música é o carro chefe deles". }\end{array}$ & $\begin{array}{l}\text { (...) "como maior produtora de cultura do país, [a } \\
\text { Emissora] não pode ficar indiferente à força } \\
\text { artística da música gospel". }\end{array}$ \\
\hline $\begin{array}{l}\text { A rotina dos popstars } \\
\text { da fé. }\end{array}$ & $\begin{array}{l}\text { a pureza da mensagem divina e a lógica } \\
\text { violenta do mercado? Como administram fé, } \\
\text { carreira artística, vida religiosa, família, } \\
\text { viagens, fãs, sucesso e dinheiro? }\end{array}$ & $\begin{array}{l}\text { Nomes como Aline Barros, Ana Paula Valadão e } \\
\text { Regis Danese são verdadeiras potências capazes } \\
\text { de arrastar centenas de milhares de pessoas a } \\
\text { shows, cruzar barreiras religiosas e vender } \\
\text { milhões de discos e DVDs. }\end{array}$ \\
\hline
\end{tabular}

\begin{tabular}{|l|l|l|}
\hline \multicolumn{1}{|c|}{ TÍTULO } & \multicolumn{1}{c|}{ DIALÉTICA } & \multicolumn{1}{c|}{ INDÚSTRIA CULTURAL } \\
\hline $\begin{array}{l}\text { Mercado evangélico } \\
\text { faz girar cerca de R\$ } \\
15 \text { bi por ano com } \\
\text { vendas de CDs e } \\
\text { vestuários }\end{array}$ & $\begin{array}{l}\text { O segmento gospel é o principal responsável } \\
\text { pela sobrevida da indústria fonográfica. }\end{array}$ & $\begin{array}{l}\text { Não à toa, a Sony Music criou, em 2010, um selo } \\
\text { específico para a música evangélica no Brasil. }\end{array}$ \\
\hline $\begin{array}{l}\text { O gospel é a próxima } \\
\text { onda brasileira, diz } \\
\text { executivo que lançou } \\
\text { Michel Teló }\end{array}$ & $\begin{array}{l}\text { O que eu quis dizer é que é necessário abrir } \\
\text { com muito cuidado essa porta. Primeiro porque } \\
\text { você está tratando com a fé das pessoas. Não é } \\
\text { só música, arte e dinheiro. É arte, dinheiro e fé. }\end{array}$ & $\begin{array}{l}\text { O hit do mercado gospel é muito diferente do hit } \\
\text { no mercado secular? Ele tem alguns dos mesmos } \\
\text { elemes. Você precisa de uma melodia simples } \\
\text { que apele uma grande massa de pessoas (...). }\end{array}$ \\
\hline
\end{tabular}

\begin{tabular}{|c|c|c|}
\hline TÍTULO & DIALÉTICA & INDÚSTRIA CULTURAL \\
\hline $\begin{array}{l}\text { Com crescimento de } \\
15 \% \text { ao ano, Música } \\
\text { Gospel brasileira } \\
\text { ganha novo selo } \\
\text { voltado ao estilo }\end{array}$ & $\begin{array}{l}\text { Reunindo mais de um estilo musical em torno } \\
\text { de um conceito o de canções com temática } \\
\text { evangélico-cristã o gospel passou a ser uma } \\
\text { fatia considerável do mercado e tem chamado a } \\
\text { atenção já há alguns anos. }\end{array}$ & $\begin{array}{l}\text { Com vistas no poder de compra do consumidor } \\
\text { evangélico, até a Rede Globo investiu pesado no } \\
\text { mercado criando uma programação de eventos } \\
\text { voltados para o público alvo nos últimos anos. }\end{array}$ \\
\hline $\begin{array}{l}\text { Música gospel abraça } \\
\text { diversos estilos e cria } \\
\text { segmento de mercado } \\
\text { atraente e lucrativo }\end{array}$ & $\begin{array}{l}\text { (...) falou também sobre a controvérsia entre a } \\
\text { lógica mercadológica e a fé cristã, que é motivo } \\
\text { para críticas dentro e fora das igrejas } \\
\text { evangélicas. }\end{array}$ & $\begin{array}{l}\text { Porém, a grande vantagem da música gospel está } \\
\text { no engajamento de seu público, o que reflete } \\
\text { diretamente nos números de vendas. }\end{array}$ \\
\hline $\begin{array}{l}\text { Mercado da música } \\
\text { gospel movimenta } \mathrm{R} \$ \\
1,5 \text { bilhão e atrai } \\
\text { gigantes do mercado } \\
\text { fonográfico }\end{array}$ & $\begin{array}{l}\text { "O gospel se firmou como uma força no } \\
\text { mercado fonográfico. E tem buscado a } \\
\text { renovação para atingir um número cada vez } \\
\text { maior de pessoas." }\end{array}$ & $\begin{array}{l}\text { O crescimento constante e chamativo da música } \\
\text { gospel despertou o interesse de gigantes do } \\
\text { mercado fonográfico, como as multinacionais } \\
\text { (...). }\end{array}$ \\
\hline
\end{tabular}

\begin{tabular}{|l|l|l|}
\hline \multicolumn{1}{|c|}{ TÍTULO } & \multicolumn{1}{|c|}{ DIALÉTICA } & \multicolumn{1}{c|}{ INDÚSTRIA CULTURAL } \\
\hline $\begin{array}{l}\text { O gospel se abre ao } \\
\text { rap, reggae e } \\
\text { eletrônica em busca } \\
\text { de renovação. }\end{array}$ & & $\begin{array}{l}\text { A repercussão nas redes sociais do trabalho de } \\
\text { artistas como o DJ PV tem sido usada como } \\
\text { medida para o mercado fonográfico avaliar o } \\
\text { alcance de suas novas "ovelhas" (...). }\end{array}$ \\
\hline $\begin{array}{l}\text { Do funk ao eletrônico: } \\
\text { artistas dão nova cara } \\
\text { à música gospel. }\end{array}$ & $\begin{array}{l}\text { Com clipes bem dirigidos, letras de adoração } \\
\text { menos óbvias e aposta na estética jovem que } \\
\text { faz sucesso no mercado secular (termo muito } \\
\text { utilizado nas igrejas para determinar o mercado } \\
\text { fora delas), esses artistas têm chegado a um } \\
\text { público até então distante da igreja. }\end{array}$ & $\begin{array}{l}\text { Não é de hoje que a indústria musical gospel está } \\
\text { aberta a novos artistas e gêneros. }\end{array}$ \\
\hline $\begin{array}{l}\text { Globo faz 5 } 5^{\circ} \text { edição } \\
\text { de seu festival gospel } \\
\text { "particular" }\end{array}$ & & $\begin{array}{l}\text { A TV Globo realiza mais uma edição do "Festival } \\
\text { Promessas", dedicado à música gospel (...). }\end{array}$ \\
\hline
\end{tabular}

Fonte: Elaborado pelos autores.

Nota: A lista de links das reportagens está inserida após as referências. 
A primeira categoria analisada foi a dialética, aqui vinculada à contradição. Na primeira reportagem, tanto o título quanto as frases separadas para análise justificam essa assertiva: "Música gospel: trinado, fé e dinheiro"; "o mercado gospel alia fé e louvor para produzir dinheiro" e ainda "recebem novos convertidos, que passam a consumir vorazmente os produtos”. Infere-se dessas frases a transformação da prática religiosa, que é uma atividade humana histórica, relevante à cultura de uma sociedade (TAME, 1984), se transformando em fonte de provisão de uma economia de mercado (COSTA, 2017).

Ao analisar as frases retiradas das notícias, percebe-se com notoriedade a conexão predominante com a indústria cultural. No quadro um, todas as reportagens preenchem a categoria em questão. A produção artística produzida em grande escala, seguindo o esquema capitalista e submetendo tanto a obra de arte, quanto o artista, ao valor de troca (ADORNO e HORKHEIMER, 2002), pode ser identificado na quarta reportagem na frase "Você precisa de uma melodia simples que apele para uma grande massa de pessoas", ditando como deve ser a música produzida. Ainda, sobre a fala presente na quarta reportagem, que a melodia e a harmonia da música em questão devem ser simples, testifica o que Adorno diz sobre o produto da Indústria cultural, que é feito "de modo que a sua apreensão adequada exige, por um lado, rapidez de percepção, capacidade de observação e competência específica, e por outro é feita de modo a vetar, de fato a atividade mental do espectador" (ADORNO e HORKHEIMER, 2002, p. 173). Nesse sentido, há uma subestimação do consumidor e manipulação no seu gosto e escolha, prédeterminados pela Indústria cultural.

Quando Adorno (1983) fala sobre a transformação da música em mercadoria, referindo-se ao fetichismo da música, ele alega que os grandes veículos de comunicação são correlatos à indústria cultural, servindo-a na divulgação e distribuição da sua produção às massas. Isso se confirma na primeira reportagem, “(...) como maior produtora de cultura do país, [a Emissora] não pode ficar indiferente à força artística da música gospel”.

Se o produto é famoso então ele ganhou o gosto do consumidor. O objetivo, portanto, é fazer com que essa música seja conhecida por todos. Quanto mais conhecida a música for, mais as pessoas gostam dela. Essa afirmação está presente no sétimo noticiário na frase: “ $A$ repercussão nas redes sociais do trabalho de artistas como o DJ PV tem sido usada como medida para o mercado fonográfico avaliar o alcance de suas novas ovelhas”. Ou seja, é 
interesse da indústria cultural que a música se torne famosa, conhecida por um número expressivo de consumidores.

As reportagens reunidas para essa pesquisa foram retiradas da internet. E as revistas (e sites) responsáveis pelas reportagens visam a disseminação do seguimento. O próprio noticiário funciona como um instrumento de divulgação para o segmento de mercado em que a música gospel se tornou. As chamadas das reportagens e os títulos já denunciam essa intenção: "Música gospel abraça diversos estilos e cria segmento de mercado atraente e lucrativo" (sexta reportagem); ou "O gospel é a próxima onda brasileira, diz executivo que lançou Michel Teló" (primeira reportagem).

Ainda se verifica, nesta análise, a ausência da categoria Educação musical, como visto no quadro 1. As empresas que divulgam essas reportagens demonstram pouco interesse na formação ou educação musical. A categoria educação musical não comparece justamente porque o interesse dos grandes veículos de comunicação está na homogeneização do gosto. A educação musical remete à formação, a autonomia, a criatividade e, por conseguinte à reflexão crítica (PUCCI, OLIVEIRA e ZUIN, 2008).

\subsection{Entrevistas}

As entrevistas aconteceram com pessoas que vivem a música gospel em sua prática religiosa. Todos atuam como líderes musicais em suas respectivas comunidades. Eles coordenam os ensaios e decidem o repertório a compor o ato religioso. A maioria dos entrevistados se dedica ao serviço de forma voluntaria.

No quadro 2, a seguir, foram organizados os principais dados coletados das entrevistas. Na composição do quadro estão dispostos o perfil dos entrevistados (idade, formação, o tempo de atuação no serviço religioso e a habilidade musical) e as categorias: Dialética, Indústria cultural e Educação musical.

QUADRO 2 - Análise preliminar das entrevistas

\begin{tabular}{|l|l|l|l|l|l|}
\hline \multicolumn{1}{|c|}{ PERFIL } & Idade e \\
$\begin{array}{c}\text { formação } \\
\text { escolar }\end{array}$ & $\begin{array}{c}\text { Tempo } \\
\text { de } \\
\text { atuação }\end{array}$ & $\begin{array}{c}\text { Instrumento } \\
\text { musical }\end{array}$ & DIALÉTICA & INDÚSTRIA CULTURAL & $\begin{array}{c}\text { EDUCAÇÃO } \\
\text { MUSICAL }\end{array}$ \\
\hline $\begin{array}{l}35 \text { anos / } \\
\text { Ensino } \\
\text { Médio }\end{array}$ & 17 anos & $\begin{array}{l}\text { Baixo } \\
\text { eletrônico, } \\
\text { saxofone e } \\
\text { voz }\end{array}$ & & $\begin{array}{l}\text { "Seleciono as músicas da } \\
\text { internet" (...) "o que está } \\
\text { acontecendo no momento } \\
\text { na música gospel". }\end{array}$ & Formar outras equipes \\
\hline
\end{tabular}




\begin{tabular}{|c|c|c|c|c|c|}
\hline $\begin{array}{l}50 \text { anos / } \\
\text { Ensino } \\
\text { Médio }\end{array}$ & 33 anos & $\begin{array}{l}\text { Teclado, } \\
\text { baixo } \\
\text { eletrônico, e } \\
\text { voz }\end{array}$ & $\begin{array}{l}\text { (...) "preparar as } \\
\text { pessoas para servirem } \\
\text { a Deus e andar com } \\
\text { Deus através da } \\
\text { música”. }\end{array}$ & $\begin{array}{l}\text { "Eu tento escolher } \\
\text { músicas que a letra seja } \\
\text { forte e verdadeira". "Que } \\
\text { faça parte do dia a dia da } \\
\text { gente". "Procuro me } \\
\text { inteirar daquilo que está } \\
\text { sendo a atualidade". }\end{array}$ & $\begin{array}{l}\text { "Tudo que eu sei e } \\
\text { que eu faço hoje, mais } \\
\text { ou menos de } \\
\text { autodidata". "deixar } \\
\text { uma geração de } \\
\text { músicos". }\end{array}$ \\
\hline $\begin{array}{l}40 \text { anos / } \\
\text { Ensino } \\
\text { Médio }\end{array}$ & 18 anos & $\begin{array}{l}\text { Teclado e } \\
\text { voz }\end{array}$ & & $\begin{array}{l}\text { "Veículos de } \\
\text { comunicação. Primeiro } \\
\text { impacto, você escuta, } \\
\text { você gosta. Além do } \\
\text { critério de estar sendo } \\
\text { muito tocada, muito } \\
\text { cantada também, tem esse } \\
\text { critério". }\end{array}$ & $\begin{array}{l}\text { "Eu entrei sem fazer } \\
\text { curso." }\end{array}$ \\
\hline
\end{tabular}

\begin{tabular}{|c|c|c|c|c|c|}
\hline \multicolumn{3}{|c|}{ PERFIL } & \multirow[b]{2}{*}{ DIALÉTICA } & \multirow[b]{2}{*}{ INDÚSTRIA CULTURAL } & \multirow[b]{2}{*}{$\begin{array}{c}E D U C A C ̧ \tilde{A} O \\
M U S I C A L\end{array}$} \\
\hline $\begin{array}{c}\text { Idade e } \\
\text { formação } \\
\text { escolar }\end{array}$ & $\begin{array}{c}\text { Tempo } \\
\text { de } \\
\text { atuação }\end{array}$ & $\begin{array}{c}\text { Instrumento } \\
\text { musical }\end{array}$ & & & \\
\hline $\begin{array}{l}39 \text { anos / } \\
\text { Superior }\end{array}$ & 20 anos & $\begin{array}{l}\text { Teclado e } \\
\text { Voz }\end{array}$ & $\begin{array}{l}\text { (...) "é levar a equipe a } \\
\text { entender o que ela faz. } \\
\text { Louvor não é só } \\
\text { cantar". }\end{array}$ & $\begin{array}{l}\text { "São selecionadas de } \\
\text { acordo com a temática do } \\
\text { culto, podendo ser } \\
\text { direcionado pelo líder } \\
\text { superior que vai conduzir } \\
\text { o ou não". (...) "às vezes } \\
\text { ouve na rádio". }\end{array}$ & $\begin{array}{l}\text { "Tem que ser um } \\
\text { conjunto. Quando a } \\
\text { gente estuda música a } \\
\text { gente sempre vê falar } \\
\text { na excelência. Não } \\
\text { adianta a pessoa dizer } \\
\text { "ah, meu ministério é } \\
\text { música" e não ter } \\
\text { habilidade nenhuma, e } \\
\text { nem querer } \\
\text { desenvolver essa } \\
\text { habilidade também. É } \\
\text { um crescente". }\end{array}$ \\
\hline $\begin{array}{l}32 \text { anos / } \\
\text { Cursando } \\
\text { Superior }\end{array}$ & 15anos & $\begin{array}{l}\text { Violão, } \\
\text { teclado e } \\
\text { voz. }\end{array}$ & & $\begin{array}{l}\text { "Se o pastor não pedir } \\
\text { nenhuma, vai a que eu } \\
\text { tiver mais afinidade para } \\
\text { tocar. O critério é a que } \\
\text { encaixa melhor na minha } \\
\text { voz". }\end{array}$ & $\begin{array}{l}\text { "Ela tem que buscar } \\
\text { conhecimento prático } \\
\text { também. Eu estou } \\
\text { sempre estudando, } \\
\text { sempre aprendendo". }\end{array}$ \\
\hline
\end{tabular}

Fonte: Elaborado pelos autores.

O perfil dos entrevistados porta algumas características semelhantes como, por exemplo, o fato de que todos são músicos instrumentistas e cantores. A respeito da formação escolar, dois dos entrevistados possuem ensino superior e os quatro restantes têm até o ensino médio.

Foram retiradas das respostas dos entrevistados frases ou palavras que fizessem conexão às categorias analisadas. Konder (1994) afirma que, pensar as contradições da nossa realidade, refletindo sobre seu estado constante de transformação, é pensar dialeticamente. Quando o quarto entrevistado diz que o seu objetivo como líder de grupo musical "é criar um senso crítico nas pessoas que estão em minha volta", remete-nos à questão da Dialética. Porquanto, refletir sobre a música que é tocada, sobre a sua função e influência, remete-nos ao significado dialético dessa 
música no contexto em questão, pois pode ser tanto uma ferramenta para o serviço religioso e social, quanto pode ser instrumento de alienação e manipulação, mesmo inconscientemente.

A segunda categoria exposta no quadro 2 foi a Indústria cultural. Ela comparece na fala do primeiro entrevistado, quando disse: "que está acontecendo no momento na música gospel”; na resposta do segundo entrevistado: "Procuro me inteirar daquilo que está sendo a atualidade”; e na do terceiro entrevistado: "Por estar no mercado, como se diz, está em evidência, essa música”. Os entrevistados demonstraram se importar com o que é novidade na música, no sentido de novas produções. Todavia, é justamente o que Adorno e Horkheimer (2002) explicam sobre o 'novo' implantado pela Indústria cultural, onde existe uma necessidade de efeitos novos, mas que na verdade estão apensos ao velho esquema. Fica evidente outro aspecto da Indústria cultural na fala dos entrevistados quando dizem a respeito do critério de seleção para o repertório utilizado. Eles mencionaram que selecionam as músicas do rádio ou da internet, ou seja, conhecem as músicas através de veículos de comunicação em massa. Com isso, essas fontes são colaboradoras em imprimir valores que são interessantes para o expectador, visto como um consumidor em potencial.

Na categoria Educação musical, prevalece na fala dos entrevistados, a escassez de uma formação musical nos grupos. O quarto entrevistado diz que a música que eles utilizam na comunidade "precisa ser melhorada", e o quinto entrevistado afirma não ser suficiente dizer que faz o trabalho "e não ter habilidade nenhuma e nem querer desenvolver essa habilidade”, confirma a necessidade e importância da educação musical nesse contexto.

Nas falas do terceiro entrevistado: "Eu entrei sem fazer curso"; e do segundo entrevistado: “(...) faço hoje, mais ou menos de autodidata”, - demonstram que eles desenvolvem suas habilidades musicais convivendo com outros músicos deste contexto.

Outro aspecto que pode ser identificado, conexo a essa categoria, está na fala do primeiro entrevistado: sobre "formar outras equipes"; mostrando interesse em formar outros músicos para o ofício e; na fala do segundo entrevistado: sobre "deixar uma geração de músicos”. Assim, verifica-se que o trabalho formativo com esses grupos musicais é um campo de possibilidades para a educação musical. A educação musical teria participação também na fala do quarto entrevistado quando se refere à música que utiliza como sendo uma ferramenta para anunciar seus ensinamentos, mas que "falta ser descoberta musicalmente". Para esse entrevistado, a formação musical ainda não tem prioridade nesse contexto. 
O quadro 3 a seguir mostra as músicas citadas pelos entrevistados, acompanhadas dos seus intérpretes. Esse quadro serviu para identificar as músicas que os entrevistados usam nos grupos musicais e nas reuniões religiosas.

QUADRO 3 - Músicas citadas pelos entrevistados

\begin{tabular}{|l|l|c|}
\hline \multicolumn{1}{|c|}{ MÚSICA } & \multicolumn{1}{c|}{ CANTOR } & CITAÇÕES \\
\hline A minha família é benção do senhor & Regis Danese & 2 \\
\hline Amigo de Deus & Ademar de Campos & 1 \\
\hline Grande é o Senhor & Ademar de Campos & 1 \\
\hline Lugar Seguro & Aline Barros & 3 \\
\hline Ressuscita-me & Aline Barros & 2 \\
\hline Sonda-me & Aline Barros & 1 \\
\hline Abraça-me & André Valadão & 2 \\
\hline Eu e minha casa serviremos a Deus & André Valadão & 1 \\
\hline Fé & André Valadão & 1 \\
\hline Aclame ao Senhor & Diante do Trono & 1 \\
\hline Me ama & Diante do Trono & 1 \\
\hline Seu sangue & Fernandinho & 1 \\
\hline Uma nova história & Fernandinho & \\
\hline
\end{tabular}

\begin{tabular}{|l|l|c|}
\hline \multicolumn{1}{|c|}{ MÚSICA } & \multicolumn{1}{c|}{ CANTOR } & CITAÇÕES \\
\hline Atrai o meu coração & Filhos do Homem & 1 \\
\hline Deus tu és grande & Gui Rebustine & 1 \\
\hline Brasil & João Alexandre & 1 \\
\hline Feirante & João Alexandre & 1 \\
\hline Volta & Leonardo Gonçalves & 1 \\
\hline Os sonhos de Deus & Ludmila Ferber & 1 \\
\hline Eu creio que tudo é possível & Ministério Fonte da Vida & 1 \\
\hline Geração apostólica & Ministério Fonte da Vida & 1 \\
\hline Move as águas & Ministério Fonte da Vida & 1 \\
\hline Tua memória & Ministério Fonte da Vida & 1 \\
\hline Viver por fé & Ministério Fonte da Vida & 2 \\
\hline Reina em mim & Nívea Soares & 1 \\
\hline Teu amor não falha & Nívea Soares & 1 \\
\hline Fornalha & Pedras Vivas & 1 \\
\hline O grito & Pedras Vivas & 1 \\
\hline
\end{tabular}

\begin{tabular}{|l|l|c|}
\hline \multicolumn{1}{|c|}{ MÚSICA } & \multicolumn{1}{c|}{ CANTOR } & CITAÇÕES \\
\hline Oceano de amor & Pedras Vivas & 4 \\
\hline Pai nosso & Pedras Vivas & 2 \\
\hline Tocar em ti & Pedras Vivas & 1 \\
\hline Conheci um grande amigo & Rebanhão & 1 \\
\hline Faz Um Milagre em Mim & Regis Danese & 2 \\
\hline Eu vou viver o meu milagre & Renascer Praise & 1 \\
\hline Lugares altos & Renascer Praise & 1 \\
\hline No caminho do milagre & Renascer Praise & 1 \\
\hline Ar & Thalles Roberto & 1 \\
\hline Deus da minha vida & Thalles Roberto & 2 \\
\hline Faz chover & Trazendo a Arca & 1 \\
\hline Eu te busco & Vineiard & 1 \\
\hline Reina em mim & Vineiard & 1 \\
\hline
\end{tabular}

Fonte: Elaborado pelos autores. 
Pelo quadro 3 foi possível identificar as músicas e os cantores que mais foram citados pelos entrevistados. A música 'Oceano de Amor' do grupo Pedras Vivas, seguida de 'Lugar Seguro' da cantora Aline Barros. Os artistas ou grupos mais citados foram: Pedras Vivas (9 vezes), Ministério Fonte da Vida (7 vezes), Aline Barros (6 vezes) e André Valadão (4 vezes). Por meio de uma análise mais atenta desta lista de canções e artistas mais citados, pode-se perceber que a grande maioria destes pertencem às grandes gravadoras, em contraste com uma minoria de canções de cantores independentes.

\subsection{Grupo Focal}

Para a terceira coleta de dados da pesquisa, foi elaborado um grupo focal, baseado nas orientações metodológicas de Gatti (2012). O grupo focal foi composto por quatro integrantes que participam de grupos musicais em contextos religiosos. Para a análise dos dados do grupo focal, foi elaborado o quadro 4 , a seguir.

QUADRO 4 - Análise preliminar do grupo focal

\begin{tabular}{|c|c|c|c|c|c|}
\hline 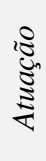 & 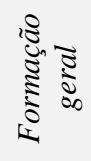 & 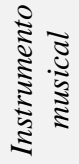 & DIALÉTICA & INDÚSTRIA CULTURAL & EDUCAÇÃO MUSICAL \\
\hline $\begin{array}{l}\text { O̊ } \\
\text { ే } \\
\beth\end{array}$ & 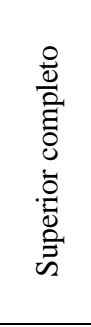 & ${ }_{>}^{N}$ & $\begin{array}{l}\text { "Críticas também } \\
\text { podem construir uma } \\
\text { situação de } \\
\text { crescimento; mas é } \\
\text { você ter a humildade de } \\
\text { saber que sempre você } \\
\text { precisa melhorar } \\
\text { independentemente de } \\
\text { onde você esteja". }\end{array}$ & $\begin{array}{l}\text { “(...) geralmente, não utilizo } \\
\text { um critério fixo.” “(...) as } \\
\text { músicas que são interessantes } \\
\text { para a gente cantar na igreja, } \\
\text { e que a igreja tem uma } \\
\text { receptividade maior a gente } \\
\text { trás pra cá. Mas é através do } \\
\text { rádio mesmo”. }\end{array}$ & $\begin{array}{l}\text { "Mas eu sempre tive essa vontade. } \\
\text { Mas curso, preparação, assim, questão } \\
\text { vocal, eu nunca fiz". (...) "não existe } \\
\text { muito essa questão da "formação } \\
\text { musical. (...) as pessoas integrantes da } \\
\text { equipe, elas procuram adquirir esse } \\
\text { conhecimento por conta própria e isso } \\
\text { acaba que aparece na qualidade final } \\
\text { do trabalho". }\end{array}$ \\
\hline $\begin{array}{l}\tilde{O} \\
\hat{\Xi} \\
\tilde{a}\end{array}$ & 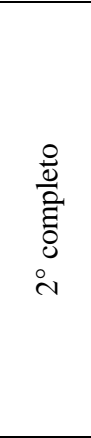 & $\begin{array}{l}\frac{20}{10} \\
\frac{10}{2} \\
0 \\
N \\
0 \\
>\end{array}$ & & $\begin{array}{l}\text { "As músicas, normalmente é } \\
\text { ouvindo rádio e quando eu } \\
\text { vou visitar alguma igreja } \\
\text { diferente eu vejo as músicas } \\
\text { que eles cantam diferentes...”. } \\
\text { "(...) A pessoa ouve e repete. } \\
\text { Ouve uma música, pega a } \\
\text { sequência e repete. A igreja é } \\
\text { carente de uma formação } \\
\text { técnica musical, a equipe que } \\
\text { cuida da parte musical da } \\
\text { igreja". }\end{array}$ & $\begin{array}{l}\text { "Também nunca fiz curso. Na verdade, } \\
\text { eu fiz algumas aulas". } \\
\text { "E se tivesse um ensino, se a igreja } \\
\text { ensinasse, tivesse cursos, palestras, } \\
\text { sobre louvor, sobre música, acho que } \\
\text { seria um crescimento para a igreja. Eu } \\
\text { acho que quem toca na igreja aprende } \\
\text { mais por conta própria. Através de } \\
\text { vídeos, youtube". }\end{array}$ \\
\hline 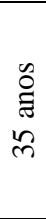 & 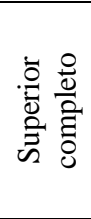 & ${ }^{N}$ & & $\begin{array}{l}\text { “(...) não só pela rádio, mas } \\
\text { também pela internet, pelo } \\
\text { youtube, em outros sites que a } \\
\text { gente conhece”. }\end{array}$ & $\begin{array}{l}\text { "Como os demais, eu também não fiz } \\
\text { um curso, mas tive noções de teoria } \\
\text { musical, sobre ritmo". “(...) sem uma } \\
\text { formação ele começa a ficar limitado. } \\
\text { Ele não consegue avançar até certo } \\
\text { ponto". }\end{array}$ \\
\hline
\end{tabular}




\begin{tabular}{|c|c|c|c|c|}
\hline 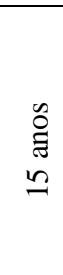 & 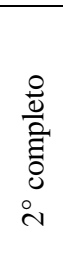 & $\stackrel{N}{\circ}$ & $\begin{array}{l}\text { "Em questão de saber uma } \\
\text { música nova, ou alguma } \\
\text { novidade, eu sempre procuro } \\
\text { pela internet". }\end{array}$ & $\begin{array}{l}\text { "Eu também não tive curso" (...) "eu } \\
\text { não estudo, não sei tocar nada, mas } \\
\text { acredito que tenho um ouvido muito } \\
\text { bom, em questão de ritmo, de notas". } \\
\text { "Aonde eu estou hoje, a equipe é bem } \\
\text { preocupada com essa questão de } \\
\text { aperfeiçoamento, formação musical". }\end{array}$ \\
\hline
\end{tabular}

Fonte: Elaborado pelos autores.

Conforme realizado nas análises anteriores, das reportagens e das entrevistas, o quadro quatro também tem na sua composição as categorias Dialética, Indústria cultural e Educação musical; bem como, informações que correspondem o perfil de cada membro, como escolaridade, tempo de atuação no trabalho eclesiástico e o instrumento musical que executa. Além disso, estão distribuídos trechos das falas dos participantes que fazem conexão às categorias aqui analisadas.

Pucci, Oliveira e Zuin (2008, p. 80) estudando sobre a Dialética negativa de Adorno, esclarecem que "a degeneração da consciência (que se converte em mitologia) é produto de sua carência de reflexão crítica sobre si mesma”, ou seja, a reflexão crítica pode evitar a alienação da consciência e possibilitar uma superação do homem em relação a si e a sua realidade. Na fala do primeiro participante: as "críticas também podem construir uma situação de crescimento, mas é você ter a humildade de saber que sempre você precisa melhorar independentemente de onde você esteja", remete-nos a negar o conhecimento alcançado, não no sentido de desconsiderar, mas de não o tê-lo como acabado e buscar um avanço qualitativo. Nas demais falas dos participantes do grupo focal, não foram identificados os elementos que fizessem conexão à categoria Dialética.

Em seguida, apontam-se nas falas dos participantes, aspectos que fazem ligação com a categoria Indústria cultural (ADORNO e HORKHEIMER, 2002). Um exemplo disso é quando os participantes afirmam que selecionam as músicas que utilizam no momento musical religioso, na maioria das vezes, da rádio ou da internet. Mais uma vez comparecem os veículos de comunicação como fontes de repertório dos músicos, por apresentarem as obras mais tocada ou da moda, o que confirma a presença da Indústria cultural.

Conexo à categoria Educação musical está a necessidade de uma formação musical, tanto dos próprios participantes do grupo focal, quanto no contexto em que estão inseridos, nos grupos musicais das suas comunidades. A começar pela identificação da atividade musical predominante, o canto. Todos os participantes alegaram não terem feito algum tipo de aula ou 
curso para participar nos grupos musicais. O primeiro participante diz que: “curso, preparação assim, questão vocal, eu nunca fiz"; o segundo participante afirma que: "aula de canto eu nunca fiz, mas tenho vontade de fazer"; e o quarto participante diz que: "também não tive curso", confirmando a falta de formação musical. Não obstante, a fala dos participantes também testifica a necessidade que sentem da formação: "e hoje vejo que está fazendo falta", primeiro participante; e "sem uma formação ele começa a ficar limitado", do terceiro participante.

Assim, verificamos que o desenvolvimento de suas habilidades musicais é resultado das experiências adquiridas pela vivência musical nos grupos e no do próprio momento litúrgico. Os participantes revelaram no grupo focal que sentem falta de oportunidades de formação musical para o trabalho que exercem. O segundo participante do grupo focal coloca que: "cursos, palestras, (...) acho que seria um crescimento"; e, tanto o primeiro, quanto o segundo participante, confirmam que suas aprendizagens foram autodidatas.

\section{CONSIDERAÇÕES FINAIS}

Ante os elementos apresentados, a intenção dessa pesquisa é refletir sobre a presença e influência da Indústria cultural no contexto da música gospel contemporânea, e, propor, por meio da educação musical, a formação como espaço de resistência frente à manipulação e alienação do arranjo capitalista na autonomia e na criatividade dos sujeitos (COSTA, 2017; ZANOLLA, 2013).

Nesse sentido, o trabalho apontou na fundamentação teórica a dialética como método de reflexão crítica necessário à formação da consciência humana (RODRIGUES, 2014), e buscou esclarecer tanto a historicidade, quanto as categorias que denunciam os efeitos da Indústria cultural (ADORNO e HORKHEIMER, 2002). Da mesma maneira, ressaltando as possibilidades da Educação musical no contexto religioso.

O trabalho constatou, através da reunião de reportagens relacionadas, que a música gospel se transformou também em um seguimento de mercado. E, por meio das entrevistas e do grupo focal com sujeitos que vivem essa música nas comunidades religiosas, foi possível notar elementos que fazem relação às categorias: Dialética, Indústria cultural e Educação musical.

A categoria mais presente nas análises foi a Indústria cultural. Nas reportagens selecionadas, as informações a respeito da música gospel, confirmam a sua vertente enquanto seguimento de mercado e denunciam a Indústria cultural presente no meio religioso do século 
XXI: as modificações no modo de produção dessa música; a perda de autonomia do artista; o empobrecimento da qualidade musical visando uma música simples, mais superficial; o ajuste feito por grandes gravadoras e produtoras, que, nesse casso, se enquadram no que Adorno (1983) chamou de 'supremos dirigentes', monopolizando o setor, padronizando a música que é produzida; o encargo dos grandes veículos de comunicação em difundir a música e de imprimir valores no que é divulgado e objetivando a vendagem.

A participação de sujeitos que trabalham com a música nestes contextos, e a manifestação de suas opiniões, contribuíram para identificar um campo aberto de possibilidades para a atuação da educação musical e sua função para a formação crítica (PUCCI, OLIVEIRA e ZUIN, 2008; COSTA, 2017). Assim, constatou-se um contexto social contemporâneo que carece de ações formativas voltadas para emancipação em relação ao sistema da Indústria cultural.

\section{REFERÊNCIAS}

ADORNO, Theodor W. O fetichismo na música e a regressão da audição. In: Benjamin, W. et al. Textos escolhidos $2^{\text {a }}$ Ed. São Paulo, 1983.

ADORNO, Theodor W.; HORKHEIMER, Max. A indústria cultural: O iluminismo como mistificação de massas In: LIMA, Luiz C. Teoria da Cultura de Massa. São Paulo: Paz e Terra, 2002.

. Dialética do esclarecimento. Rio de Janeiro: Zahar, 1985.

BARDIN, Lawrence. Análise de conteúdo. São Paulo: Almedina Brasil, 2011.

BORGES, Juliano. A dialética do esclarecimento, de Theodor Adorno e Max Horkheimer. Revista Estudos Políticos, v. 2. 2011. p.103-106.

COSTA, Cristiano A. da. Educação estética, música e formação humana: contradições da cultura à luz da teoria Adorniana. $160 \mathrm{f}$. Tese (Doutorado em Educação) - Universidade Federal de Goiás, Goiânia, 2017. Disponível em: <http://repositorio.bc.ufg.br/tede/handle/tede/7751> Acesso em 05 de junho de 2019.

CUNHA, Magali do N. Demandas pedagógicas no contexto das igrejas evangélicas no Brasil em tempos de cultura gospel. Educação e transformação, v. 31. 2007, p. 83-94.

FRANCO, Maria L. P. B. Análise de conteúdo. Brasília: Líber Livro, 2012.

FRANÇA, Fabiano L. Fetichismo e decadência do gosto musical em Adorno. Existência e Arte. Revista Eletrônica do Grupo PET - UFSJ, v. 4. 2008. p. 1-6. 
GATTI, Bernadete A. Grupo focal na pesquisa em ciências sociais humanas. Brasília: Líber Livro, 2012.

KATER, Carlos. O que podemos esperar da educação musical em projetos de ação social. Revista da $A B E M$, v. 2, n. 10. 2004. p. 43-51.

KONDER, Leandro. O que é dialética. São Paulo: Brasiliense, 1994.

LAKATOS, Eva M.; MARCONI, Marina de A. Metodologia científica. São Paulo: Atlas, 1992.

MARTINOFF, Eliane H. da S. A música evangélica na atualidade: algumas reflexões sobre a relação entre religião, mídia e sociedade. Revista da ABEM, v. 23. 2010. p. 67-74.

MUSSE, Ricardo. Cinco verbetes sobre Theodor W. Adorno. Blog da Boitempo. São Paulo. 2015. Disponível em: <http://blogdaboitempo.com.br/2015/11/19/5-verbetes-sobre-theodor-wadorno/>. Acesso: 20 jan. 2016.

NOGUEIRA, Monique A. Adorno e os tipos de comportamento musical: atualidade e limites de uma categorização. Revista Inter-Ação, v. 2. 2014. p. 297-310.

PAULA, Robson R. de. O mercado da música gospel no Brasil: aspectos organizacionais e estruturais. Revista UNIABEU, v. 9. 2012. p. 141-157.

PUCCI, Bruno; OLIVEIRA, Newton R. de; ZUIN, Antônio Á. S. Adorno: O poder educativo do pensamento Crítico. Petrópolis - RJ: Vozes, 2008.

RODRIGUEZ, Margarita V. Pesquisa Social: Contribuições do Método Materialista HistóricoDialético. In: CUNHA, Célia da. (org.). O Método Dialético na Pesquisa em Educação. Campinas, SP: Autores Associados, 2014.

SILVA, Victor L.; SENA, Daniel R. de C. Kant e Adorno: educação e autonomia. Saberes, v. 1, n. 11. 2015. p. 170-182.

SZYMANSKI, Heloisa (org.). A Entrevista na Pesquisa em Educação: a prática reflexiva. Brasília: Líber Livro, 2004.

TAME, David. O Poder Oculto da Música. São Paulo: Cultrix, 1984.

ZANOLLA, Silvia R. da S. (org.). Arte, estética e formação humana: possibilidades e críticas. Capinas-SP: Editora Alínea, 2013. 


\section{LINKS DAS REPORTAGENS}

ALBULQUERQUER, Carlos. O gospel se abre ao rap, reggae e eletrônica em busca de renovação. O Globo (Cultura), 2015. Disponível em: <http://oglobo.globo.com/cultura/musica/ogospel-se-abre-ao-rap-reggae-eletronica-em-busca-de-renovacao-17176884> Acesso em: 22 de dez. de 2016.

CARVALHO, Pedro. O gospel é a próxima onda brasileira, diz executivo que lançou Michel Teló. UOL-Música, 2014. Disponível em: <http://musica.uol.com.br/noticias/redacao/2014/02/11/o-gospel-e-a-proxima-onda-brasileira-dizexecutivo-que-lancou-michel-telo.htm> Acesso em: 11 de dez. de 2016.

CHAGAS, Thiago. Mercado da música gospel movimenta R\$ 1,5 bilhão e atrai gigantes do mercado fonográfico. Gospel+, 2015. Disponível em: <http://noticias.gospelmais.com.br/mercado-musica-gospel-movimenta-bilhao-atrai-gigantes78668.html> Acesso em: 20 de dez. de 2016.

DIAS, Thiago. Do funk ao eletrônico: artistas dão nova cara à música gospel; conheça. $U O L$ Música, 2015. Disponível em: <http://musica.uol.com.br/noticias/redacao/2015/09/15/do-funkao-eletronico-artistas-dao-nova-cara-a-musica-gospel-conheca.htm> Acesso em: $10 \mathrm{de}$ dez. de 2016.

FELTRIN, Ricardo. Globo faz $5^{\circ}$ edição de seu festival gospel "particular". UOL Tv e Famosos, 2015. Disponível em: <http://tvefamosos.uol.com.br/noticias/ooops/2015/10/01/globo-faz-5edicao-de-seu-festival-gospel-particular.htm> Acesso em: 20 de dez. de 2016.

LEVINO, Rodrigo. Música Gospel: trinados, dinheiro e fé. Veja-Abril, 2011. Disponível em: <http://veja.abril.com.br/noticia/entretenimento/musica-gospel-trinados-fe-e-dinheiro> Acesso em: 09 de dez. de 2016.

LOPES, João; CARDOSO, Rodrigo. A rotina dos popstars da fé. IstoÉ, n.2220, 2012. Disponível em: <http://www.istoe.com.br/reportagens/209097_A+ROTINA+DOS+POPSTARS+DA+FE> Acesso em: 10 de dez. de 2016.

MARTINS, Dan. Música gospel abraça diversos estilos e cria segmento de mercado atraente e lucrativo. Gospel+, 2014. Disponível em: <http://noticias.gospelmais.com.br/musica-gospelsegmento-mercado-atraente-lucrativo-96768.html> Acesso em: 20 de dez. de 2016.

Mercado evangélico faz girar cerca de R 15 bi por ano com vendas de CDs e vestuário. Estado de Minas Gerais (Economia), 2014. Disponível em: <http://www.em.com.br/app/noticia/economia/2014/01/30/internas_economia,493161/mercadoevangelico-faz-girar-cerca-de-r-15-bi-por-ano-com-vendas-de-cds-e-vestuario.shtml> Acesso em: 20 de dez. de 2016. 
PRONIN, Lizandra. Com crescimento de $15 \%$ ao ano, Música Gospel brasileira ganha novo sele voltado ao estilo. Território da Música, 2015. Disponível em: <http://www.territoriodamusica.com/noticias/?c=34913> Acesso em: 20 de dez. de 2016. 